\title{
Study on a Bioethanol Solar Reforming System with the Solar Insolation Fluctuation in Consideration of Heat Chemical Reaction*
}

\author{
Shin'ya OBARA ${ }^{* *}$ and Abeer Galal El-Sayed*** \\ **Tomakomai National College of Technology, \\ Nishikioka 443, Tomakomai, HOKKAIDO 0591275, Japan \\ E-mail: obara@indigo.plala.or.jp \\ ***Department of Electrical and Electronic Engineering, Kitami Institute of Technology \\ 165 Koen-cho, Kitami, Hokkaido 090-8507, Japan
}

\begin{abstract}
A bioethanol reforming system (FBSR) with a sunlight heat source is developed as a potential fuel supply system for distributed fuel cells. The temperature distribution of a catalyst layer in the reactor is not stable under conditions of unstable solar radiation and unstable outside air temperature; therefore, it is thought that the inversion rate of a reforming reaction will decrease. In this paper, heat transmission analysis was used in the catalyst layer of the reforming component of an FBSR, and temperature distribution, inversion rate, and process gas composition were investigated. Based on the results, the relationship between weather conditions and a hydrogen-generating rate was determined. When solar insolation was unstable, it turned out that the efficiency of the reforming component is reduced. Fluctuations of the solar insolation over a short period of time affect the hydrogen generating rate of an FBSR. Moreover, the amount of hydrogen production of an FBSR was simulated using meteorological data from a day in March and a day in August in a cold region (Sapporo). The analysis showed that efficiency of the reforming component exceeded $40 \%$ for both of the days.
\end{abstract}

Key words: Solar Reforming, Global Solar Radiation, Bioethanol, Heat Transfer, Simulation, Hydrogen Production

\section{Introduction}

The greenhouse gas discharge due to distributed small fuel cells changes greatly with methods of hydrogen supply. Thus, we are examining a system using the heat obtained from a small sunlight solar collector to reform of bioethanol into a vapor (fuel cell system with bioethanol solar reforming system (FBSR)). We propose that hydrogen will be produced when installing FBSR in a home ${ }^{1)}$, and we aim to use a layered neural network as the weather forecast method ${ }^{2-3)}$. However, all the analysis in this paper assumes steady-state hydrogen production.

By supplying the ethanol steam (fuel steam) to a catalyst layer, the reforming reaction is advanced at FBSR. Generally, a fuel inversion rate is obtained by using the temperature of the catalyst layer and the space velocity of the fuel steam. In this paper, nonsteady heat analysis is introduced into the catalyst layer that is in the reforming component. From this analysis, the distribution of temperature, inversion rate, and process gas composition is investigated. From this, the hydrogen generating rate in the non-steady of FBSR is obtained.

${ }^{*}$ Received 3 Oct., 2008 (No. 08-0702) [DOI: 10.1299/jpes.3.321] 


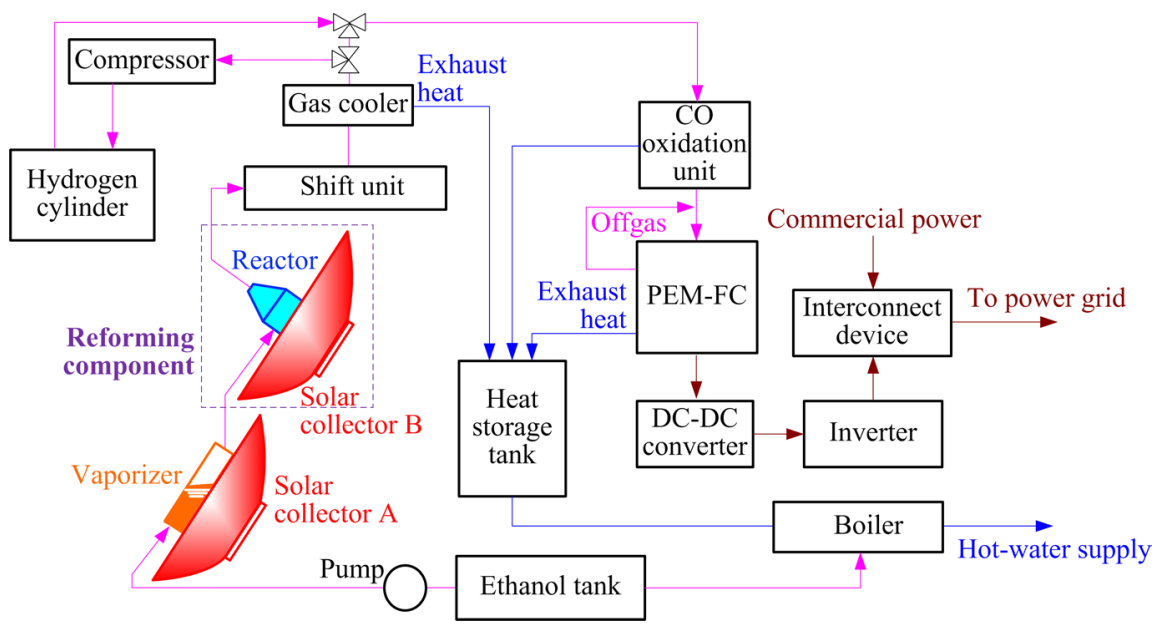

Fig. 1 Fuel cell system with bioethanol solar reforming system (FBSR)

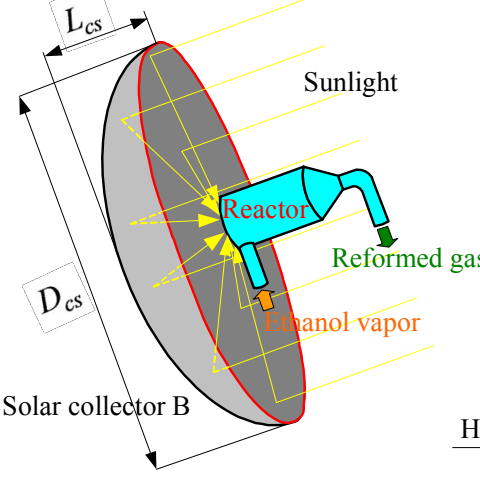

Fig. 2 Reforming component

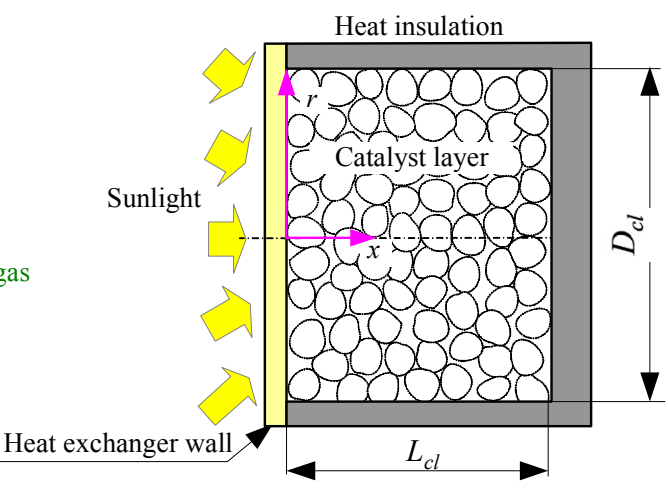

Fig. 3 Catalyst layer installed into the reactor

The solar insolation input into the acceptance surface of the reactor that is filled up with the catalyst fluctuates according to the weather. If the heat transmission characteristics of the catalyst layer are taken into consideration, it will be expected that the amount of hydrogen production of FBSR is influenced by solar insolation fluctuation over a short time. Accordingly, if the solar irradiance input into the acceptance surface of the reactor fluctuates many times in a short period, the time of the reforming reaction will not be enough. Therefore, the amount of hydrogen production of FBSR changes with characteristics of the fluctuation of solar insolation. The purpose of this research is to determine the characteristics of the amount of hydrogen production and the efficiency of the reforming component under the circumstances of global solar radiation with fluctuating inputs to the acceptance surface on the reactor of FBSR. "The higher calorific value of hydrogen / the amount of heat collections per day" defines the efficiency of the reforming component.

\section{System scheme}

\subsection{Fuel cell system with bioethanol solar reforming system (FBSR)}

Figure 1 shows the block diagram of the fuel cell system with a bioethanol solar reforming system (FBSR) ${ }^{1-3)}$. Two rotating parabolic mirrors with a solar tracking system are used for FBSR. In the following sentences, these rotating mirrors are called solar collector A and B. The high-density solar energy collector A is used for evaporation of a bioethanol fuel. The solar energy collected by solar collector B is used as the heat source for reforming of this fuel steam. 


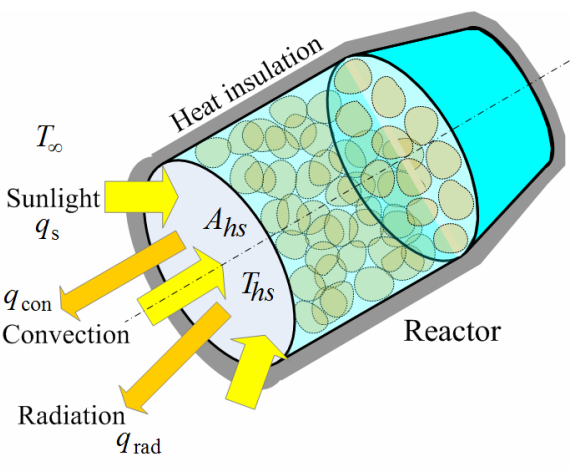

Fig. 4 Heat loss from the reactor

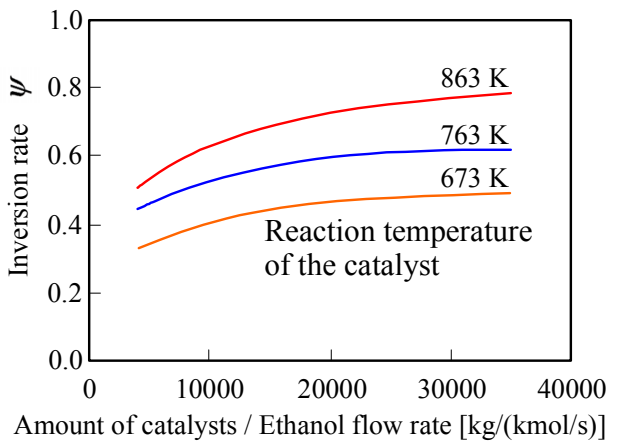

Fig. 5 Performance of the catalyst ${ }^{5)}$

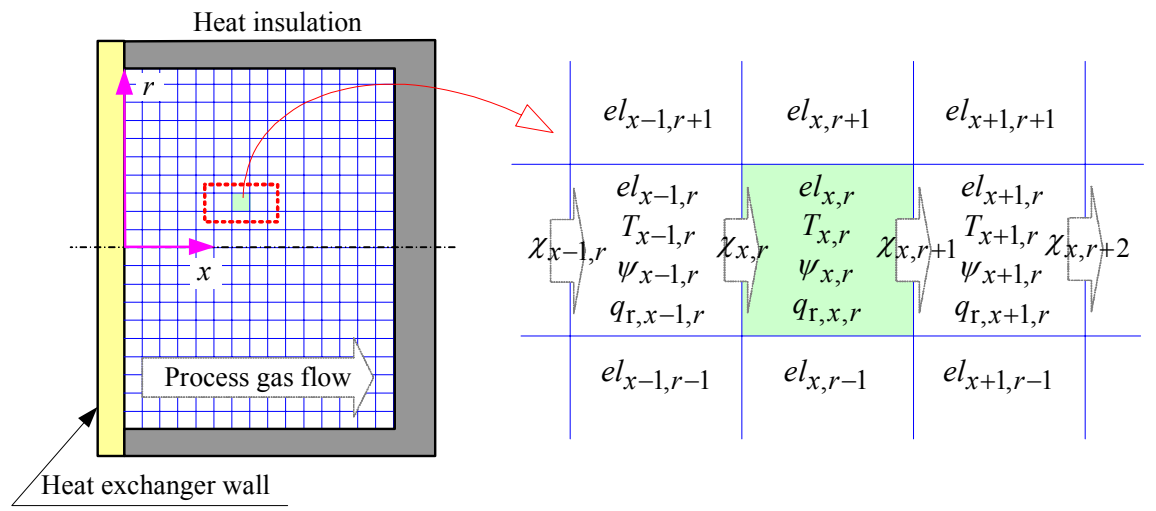

Fig. 6 Change of process gas composition

\subsection{Operation method of the system}

In order to store hydrogen, the storage tank of the reformed gas is installed in the system. While compressing and storing the reformed gas, it removes the water vapor in the gas using a cooler. The stored, reformed gas is generated by supplying a fuel cell with little solar insolation. To output power to the commercial power grid (with a regular frequency and voltage), the output of the fuel cell is converted with a DC-DC converter and an inverter. The exhaust heat from the gas cooler, the fuel cell, and the CO oxidization equipment (Fig. 1 ) is stored. This heat is supplied to the demand side of the FBSR. When supplied solar heat is insufficient, a boiler is operated.

\subsection{Reforming component}

The reforming component is shown in Fig. 2. Solar collector B has a diameter $D_{c s}$ and width $L_{c s}$. The reactor is installed in the condensing position. The heat collected using the solar collector is supplied to the catalyst layer through the end of the reactor with area $A_{h s}$ (heat-supply surface). Ethanol fuel is converted into steam beforehand using the vaporizer. It supplies this vaporized fuel to the heat-supply surface side of the reactor. In this paper, the vaporized fuel supplied to the catalyst layer is described as process gas. Process gas is reformed into gas with many hydrogen constituents by the catalyst layer. Because the reformed gas contains $\mathrm{CO}$, a shift component and a $\mathrm{CO}$ oxidation component are installed.

\section{Analysis method}

\subsection{Heat transfer of the reactor}

(1) Model of the catalyst layer and reforming reaction

Figure 3 shows the model of the catalyst layer in the reactor. The reactor has the geometry of a cylinder and it is filled up with the spherical reforming catalysts that are several millimeters in diameter. The heat collected with solar collector B is transferred to 
the heat-supply surface of the reactor, thus heating the catalyst layer. However, as shown in Fig. 4, part of the solar insolation incident on the heat-supply surface is discharged into the ambient air by convective heat transfer $q_{\text {con }}$ (Eq. (1)) and radiative heat transfer $q_{\text {rad }}$ (Eq. (2)). All of the sides of the reactor except the heat-supply surface are insulated. In the catalyst layer, heat is transferred to the reforming reaction by heat conduction of the catalyst particles, and the heat convection of process gas. When the catalyst in the reactor is distributed uniformly, the reaction rate in the whole catalyst is regulated by the space velocity of process gas, temperature distribution, pressure, etc. So, in this paper, the heat transfer between catalyst particles is handled as heat conduction of a catalyst layer. Therefore, the temperature of the catalyst layer is calculated with the convective heat transfer of process gas, the heat conduction of the catalyst layer, and reaction heat (endotherm).

$$
\begin{aligned}
& q_{c o n}=A_{h s} \cdot h_{\infty} \cdot\left(T_{h s}-T_{\infty}\right) \\
& q_{\text {rad }}=\varepsilon_{h s} \cdot A_{h s} \cdot \sigma \cdot\left(T_{h s}^{4}-T_{\infty}^{4}\right)
\end{aligned}
$$

(2) Heat convection of the catalyst layer ${ }^{4)}$

The heat convection of the catalyst layer is calculated from Eq. (3) using the $D a$ number (Damkohler) correction. The right hand side of Eq. (1) contains terms relating to the convection and chemical reaction of the process gas. $N u, R e$, and $D a$ are calculated by Eq. (4) to Eq. (6), respectively.

$$
\begin{aligned}
& N u=9.49 \cdot(\operatorname{Re} \cdot \operatorname{Pr})^{0.516} \cdot\left(D_{c} / D_{c l}\right)^{1.43}+27.2 \cdot D a^{0.325} \\
& N u=h_{g} \cdot D_{c} / \lambda_{g} \\
& R e=u_{g} \cdot D_{c} / v_{g} \\
& D a=-\left(H_{r} \cdot a_{r}\right) \cdot D_{c} /\left(\rho_{g} \cdot u_{g} \cdot C_{g} \cdot T_{g}\right)
\end{aligned}
$$

\section{(3) Reforming reaction}

Equation (7) expresses the vaporization reforming reaction of ethanol. There are several reaction paths but only the reaction in Eq. (7) is taken into consideration in this paper. The percentage of hydrogen obtained from ethanol (inversion rate) differs with catalyst temperature and the space velocity of ethanol/water vapor. Figure 5 shows the experimental result of the ethanol vapor reforming using a commercial catalyst in E. Akpan, et al ${ }^{5)}$. Figure 5 shows the relations between the amount of catalyst per flow rate of ethanol, the temperature of the catalyst layer, and the inversion rate. Fig. 5 indicates that the inversion rate is so large that there are several different catalyst fillings. Furthermore, the inversion rate is so large that temperature of the catalyst is high.

$$
\mathrm{C}_{2} \mathrm{H}_{5} \mathrm{OH}+3 \mathrm{H}_{2} \mathrm{O} \rightarrow 2 \mathrm{CO}_{2}+6 \mathrm{H}_{2}-173 \mathrm{~kJ} / \mathrm{mol}
$$

\subsection{Basic formula}

Equation (8) is the heat diffusion equation in the catalyst layer. Here, $T$ is the temperature of the catalyst layer, $r$ is the radial coordinate in the catalyst layer, and $x$ is the coordinate in the direction of the axis of the catalyst layer. The amount of endothermals 
in the catalyst layer is represented by $q_{r}, \rho_{c}, C_{c}, \lambda_{c}$, in the right hand side of Eq. (8). They represent the density of the catalyst, specific heat, and heat conductivity, respectively. $t$ is sampling time. The space element used for numerical modeling consists of an element with spatial dimensions in the direction of $r$, and the direction of $x$, for the catalyst layer with cylinder-shape shown in Fig. 3. In this paper, the following assumptions are introduced into analysis using a two-dimensional model:

(1) The catalyst and process gas are in local thermal equilibrium.

(2) The temperature dependence of physicality property values are taken into consideration.

(3) The flow velocity of process gas is uniform in the cross section.

(4) The pressure loss of the process gas is disregarded.

A discretizated version of Eq. (8) is solved under the assumptions of (1) to (4), where the boundary conditions are given in Eq. (9) to Eq. (11). Then the temperature distribution of the catalyst layer is calculated. Central differences are used in the discretized equation. The mass flow rate of the process gas is calculated using Eq. (12); and the boundary conditions in this case are Eqs. (13) and (14). $u_{g}$ in Eq. (12) is the volume flow rate of process gas, and $\rho_{g}$ is the mean density. $u_{0}$ in Eq. (14) is the volume velocity of the fuel vapor in the entrance of the catalyst layer. $u_{0}$ is the volume flow rate of the fuel vapor divided by the cross-sectional area of the catalyst layer. Equation (15) expresses the amount of endothermals created by the reforming reaction. $g_{g}, \psi$, and $H_{r}$ in the equation are the molar flow rate, the conversion ratio, and the reaction heat of process gas, respectively. If the temperature $T$ of the catalyst layer is given, then the inversion rate $\psi$ will be obtained from the performance of the catalyst. Because $H_{r}$ is determined by the reaction of Eq. (7), if $g_{g}$ is given, we can calculate the amount of endothermals $q_{\mathrm{r}}$ with the reforming reaction.

$$
\begin{aligned}
& \left(\frac{\partial^{2} T}{\partial r^{2}}+\frac{1}{r} \cdot \frac{\partial T}{\partial r}+\frac{\partial^{2} T}{\partial x^{2}}\right)+q_{\mathrm{r}}=\frac{\rho_{\mathrm{c}} \cdot C_{\mathrm{c}}}{\lambda_{\mathrm{c}}} \cdot \frac{\partial T}{\partial t} \\
& \frac{\partial T}{\partial r}=0 \quad \text { at } \quad r=R_{c l}, 0 \leq x \leq L_{c l} \\
& -\lambda_{\mathrm{c}} \cdot \frac{\partial T}{\partial x}=q_{s}-q_{\mathrm{rad}}-q_{\mathrm{con}} \\
& =q_{s}-\varepsilon \cdot \sigma \cdot\left(T_{\mathrm{s}}^{4}-T_{\infty}^{4}\right)-h \cdot\left(T_{\mathrm{s}}-T_{\infty}\right) \\
& \text { at } x=0,0 \leq r \leq R_{c l} \\
& \frac{\partial T}{\partial x}=0 \quad \text { at } \quad x=L_{c l}, \quad \frac{\partial T}{\partial r}=0 \text { at } r=0 \\
& T=T_{\infty} \text { for } t=0 \\
& \frac{\partial}{\partial x}\left(\rho_{\mathrm{g}} \cdot u_{\mathrm{g}}\right)=0 \\
& \frac{\partial u}{\partial r}=0 \quad \text { at } \quad r=R_{c l}, \frac{\partial u}{\partial x}=0 \text { at } x=L_{c l} \\
& u=u_{0} \quad \text { at } \quad x=0, \frac{\partial u}{\partial r}=0 \text { at } r=0 \\
& q_{\mathrm{r}}=g_{g} \cdot \psi \cdot H_{r}
\end{aligned}
$$




\subsection{Analysis procedure}

The model of the catalyst layer is shown in Fig. 6. The element number of the catalyst layer is expressed by $e l_{x, r}$ (with $x=1,2, \ldots, N_{x}, r=1,2, \ldots, N_{r}$ ). First, the surface temperature $T_{h s}$ of the heat-supply-surface of the reactor is calculated. $T_{h s}$ is calculated from heat capacity of the heat-supply-surface, the input heat of solar insolation $q_{\mathrm{s}}$, and heat release by convective heat transfer $q_{\text {con }}$ and radiation heat transfer $q_{\text {rad }}$ (Eqs. (1) and (2)). The temperature distribution $\left(T_{x, r}\right)$ of the catalyst layer is obtained by introducing a calculus of finite differences into Eq. (8) under boundary-conditions Eq. (9) to Eq. (11). The Gauss Seidel method is used to check for convergence of the calculus of finite differences. Once the temperature distribution $T_{x, r}$ is calculated, the inversion rate $\left(\psi_{x, r}\right)$ in each element will be found from the relations of the catalyst performance and temperature which were shown in Fig. 5. According to this $\psi_{x, r}$, the amount of endothermals $\left(q_{r, x, r}\right)$ created by the reforming reaction of the process gas is obtained from Eq. (15). From the relations shown in Fig. 6, the gas composition in the outlet of element $e l_{x-1, r}$ can be calculated from the composition of the process gas in element $e l_{x, r}$ of the outlet. The temperature distribution $\left(T_{x, r}\right)$ of the catalyst layer is again calculated using the result of the amount of endothermals created by the reforming reaction. This calculation is iterated to convergence of the discretization equation of Eq. (8). At each sampling time, the same convergence calculation is carried out and the convergence solution at $T_{x, r}$ is obtained. Once the convergence solution at $T_{x, r}$ in each sampling time is obtained, the inversion rate distribution and distribution of gas composition will be determined.

\subsection{Efficiency of reforming component}

The efficiency of reforming component is defined by the ratio of the higher calorific power of the amount of hydrogen production to the solar irradiance of the solar collectors $\mathrm{A}$ and B. Equation (16) is the formula for the efficiency of the reforming component. Taking into account the generation efficiency of a fuel cell and the power consumption in auxiliary machinery, an FBSR with a reforming component efficiency of $30 \%$ is highly efficient when compared with a solar cell with conversion efficiency $15 \%$. In this research, the efficiency of reforming component is set to $30 \%$.

$\eta_{s}=\frac{\text { Higher calorific power of the amount of hydrogen production }}{\text { The amount of solar irradiance of the solar collectors A and B }}=\frac{Q_{h}}{Q_{A}+Q_{B}}$

\section{Case analysis}

\subsection{Specification of reforming component}

In this section, it assumes introducing the FBSR into an individual house. The specifications concerning the reforming component of this FBSR are shown in Table 1. A commercial supported-catalyst is used for the reforming catalyst introduced into the analysis. A support of this catalyst is spherical alumina, and the support is adsorbed in a nickel alloy. The reacting characteristics concerning the ethanol reforming experiment using this catalyst are described in the reference 5. In this analysis, the outside air temperature $T_{\infty}$ is set to $273 \mathrm{~K}, 293 \mathrm{~K}$, and $308 \mathrm{~K}$. The heat transfer coefficient $h_{\infty}$ in Eq. (1) is set to 10 $\mathrm{W} / \mathrm{m}^{2} \mathrm{~K}$, assuming natural convection. Moreover, $\varepsilon_{h s}$ in Eq. (2) gives 0.95 assuming a black body. The area $A_{h s}$ of the heat-supply-surface of the reactor is $0.005 \mathrm{~m}^{2}$. The 
Table 1 Specification of the reforming unit

\begin{tabular}{|l||c|}
\hline Concentration area of the solar collector A and B & $1.0 \mathrm{~m}^{2}$ \\
Length of the catalyst layer $\left(L_{c l}\right)$ & $60 \mathrm{~mm}$ \\
Diameter of the catalyst layer $\left(D_{c l}\right)$ & $80 \mathrm{~mm}$ \\
Particle diameter of the catalyst $\left(D_{c}\right)$ & $3.0 \mathrm{~mm}$ \\
Steam/carbon ratio & 2.0 \\
Catalyst filling factor & 0.85 \\
\hline
\end{tabular}

Table 2 Analysis condition

\section{Sampling time}

The number of element of $x$-axis $\left(N_{x}\right)$

The number of element of $r$-axis $\left(N_{r}\right)$

Density of the catalyst

Heat conductivity of the catalyst

$0.01 \mathrm{~s}$
30
40
$213 \mathrm{~kg} / \mathrm{m}^{3}$
$10 \mathrm{~W} / \mathrm{mK}$

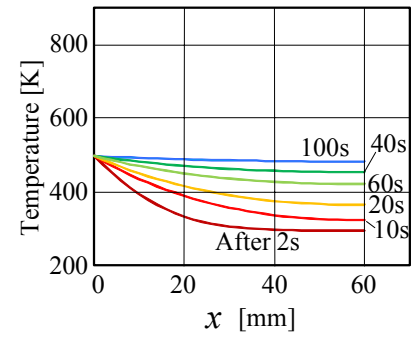

(a) $250 \mathrm{~W} / \mathrm{m}^{2}$

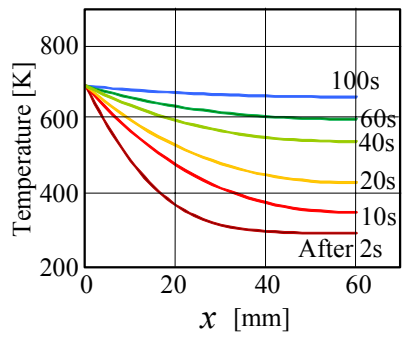

(b) $500 \mathrm{~W} / \mathrm{m}^{2}$

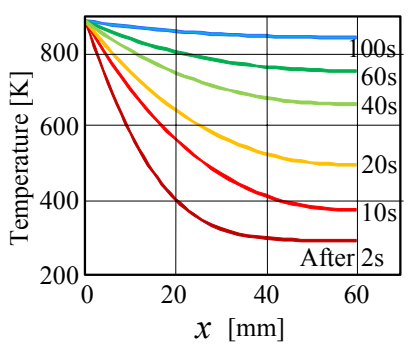

(c) $1000 \mathrm{~W} / \mathrm{m}^{2}$

The amount of heat collection by the solar collector B

Fig. 7 Temperature distribution in the catalyst layer. Outside air temperature $293 \mathrm{~K}$.

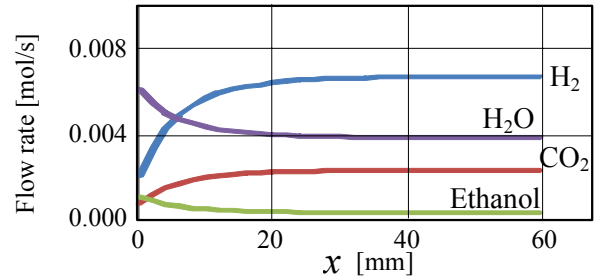

After 2 seconds

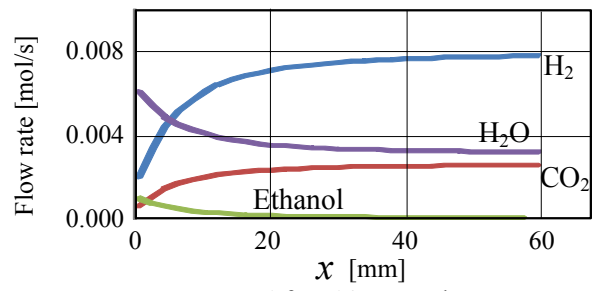

After 10 seconds

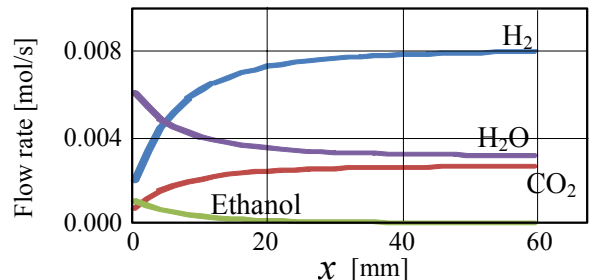

After 20 seconds

(a) The amount of heat collection by the solar collector B is $250 \mathrm{~W} / \mathrm{m}^{2}$

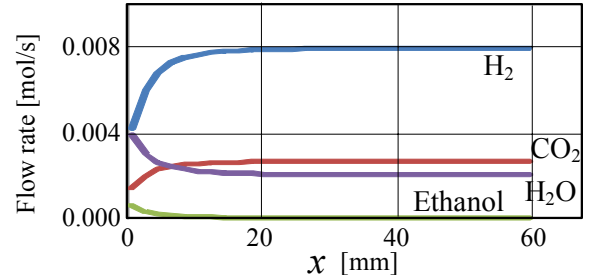

After 2 seconds

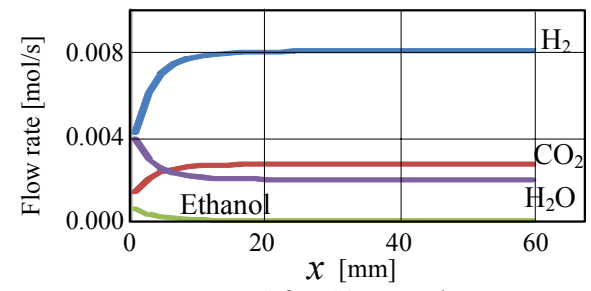

After 10 seconds

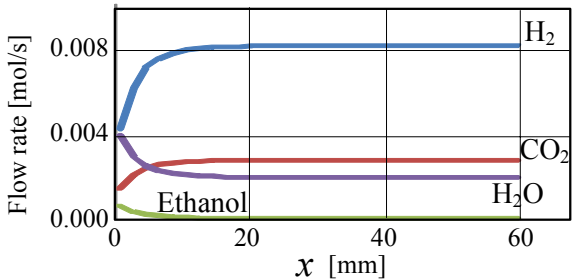

After 20 seconds

(b) The amount of heat collection by the solar collector B is $500 \mathrm{~W} / \mathrm{m}^{2}$

Fig. 8 Flow rate of process gas in the catalyst layer. Outside air temperature $293 \mathrm{~K}$.

diameter $D_{c l}$ of the catalyst layer is $80 \mathrm{~mm}$, and the width $L_{c l}$ is $60 \mathrm{~mm}$. If the reactor is filled with reforming catalysts of a mean particle diameter $3 \mathrm{~mm}$, the filling factor is 0.85 .

The transmission of the heat exchange wall of the reactor is decided to be 0.9. Moreover, the condensing efficiency of the solar collector is 0.9 . The cause of condensing loss is mainly a distortion and the soil of the mirror plane. 


\subsection{Analysis conditions and operating condition}

Analysis conditions are shown in Table 2. The analysis element was set up in the direction of $r$ and the direction of $x$ of the catalyst layer, with spacings of $2 \mathrm{~mm}$. The numbers of analysis elements were $N_{x}=30$ and $N_{r}=40$, respectively. The sampling interval time was $0.01 \mathrm{~s}$ and the analysis is calculated for a maximum $600 \mathrm{~s}$. In the analysis of the discretization formula of Eq. (8), a convergence condition was set to $10^{-5}$. S/C (molar ratio of steam to ethanol) of the ethanol fuel supplied to the vaporizer was 2.0. The fuel supply (amount of catalysts $[\mathrm{kg}] /$ ethanol flow rate $[\mathrm{kmol} / \mathrm{s}]$ ), shown on the horizontal axis shown in Fig. 5, was set as $35000 \mathrm{~kg} /(\mathrm{kmol} / \mathrm{s})$. In this paper, we analyze cases of 250,500 , and $1000 \mathrm{~W} / \mathrm{m}^{2}$ of energy incident upon the solar collector $q_{\mathrm{s}}$ (Where these are the amount of global solar radiation). Although three different values were analyzed for $T_{\infty}$ and $q_{\mathrm{s}}$, respectively, the solution concerning arbitrary $T_{\infty}$ and $q_{\mathrm{s}}$ was obtained using proportion interpolation.

\section{Analysis result}

\subsection{Temperature distribution of the catalyst layer}

Figure 7 shows the analysis result of the temperature distribution of the catalyst layer. When solar radiation is input into the heat-supply surface, the time to reach the maximum temperature is set to $0 \mathrm{~s}$. The supply to the reactor of the fuel steam (ethanol solution) is started at $0 \mathrm{~s}$. The temperature of the heat-supply surface with a solar irradiance of 250 $\mathrm{W} / \mathrm{m}^{2}$ when the outdoor temperature $293 \mathrm{~K}$ is about $500 \mathrm{~K}$. The temperature of the heat-supply surface if the time of solar irradiance is $1000 \mathrm{~W} / \mathrm{m}^{2}$ is about $890 \mathrm{~K}$. The fuel steam temperature of the reactor entrance was set up similarly to the heat-supply surface. As the fuel inversion rate increases, the catalyst temperature in the reactor gets higher. Therefore, the temperature distribution of the catalyst layer differs greatly, so that there is much solar radiation.

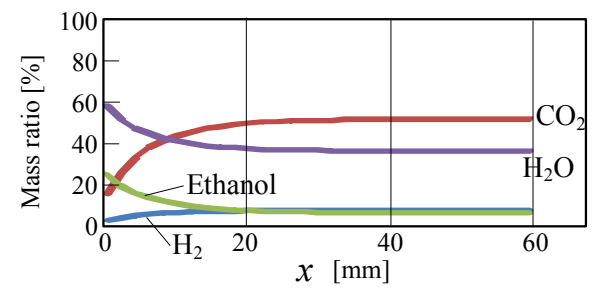

After 2 seconds

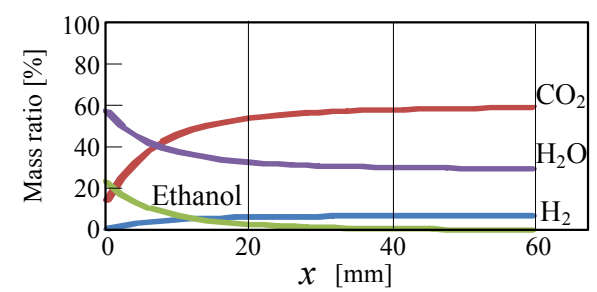

After 10 seconds

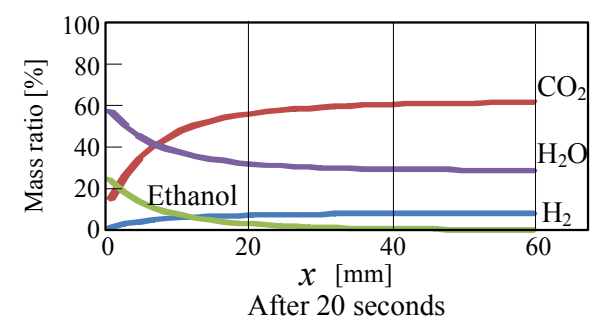

(a) The amount of heat collection by the solar collector B is $250 \mathrm{~W} / \mathrm{m}^{2}$

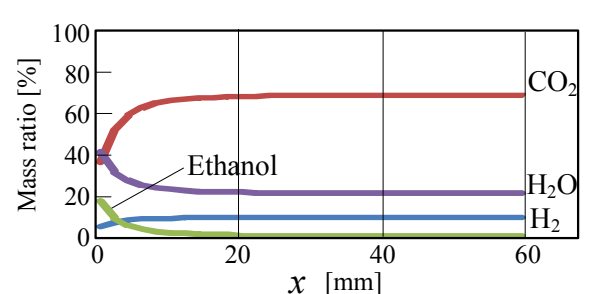

After 2 seconds

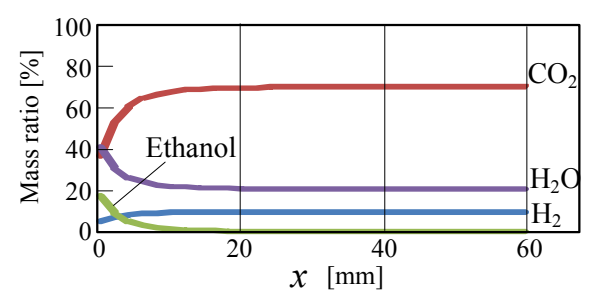

After 10 seconds

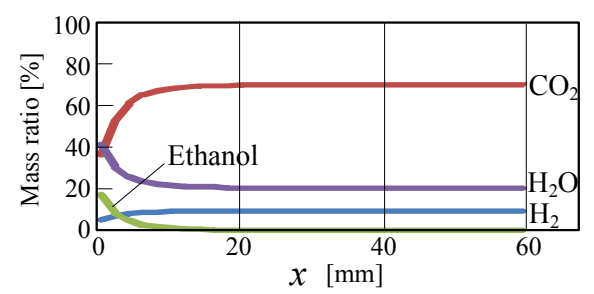

After 20 seconds

(b) The amount of heat collection by the solar collector B is $500 \mathrm{~W} / \mathrm{m}^{2}$

Fig. 9 Mass ratio distribution of process gas in the catalyst layer. Outside air temperature $293 \mathrm{~K}$. 


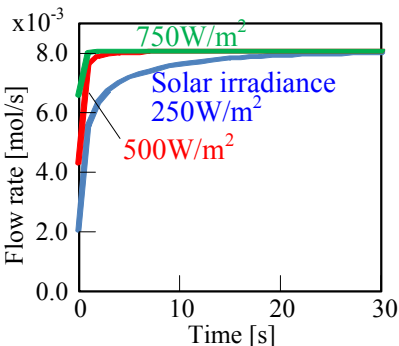

(a) $273 \mathrm{~K}$

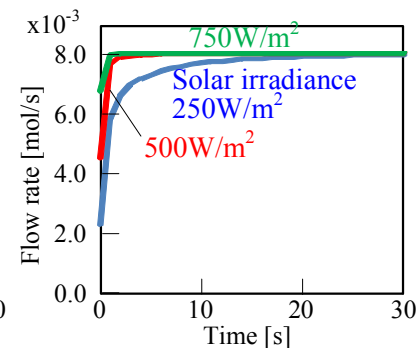

(b) $293 \mathrm{~K}$

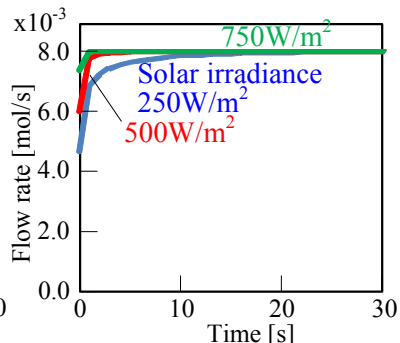

(c) $308 \mathrm{~K}$

Outside air temperature

Fig. 10 Flow rate of hydrogen production

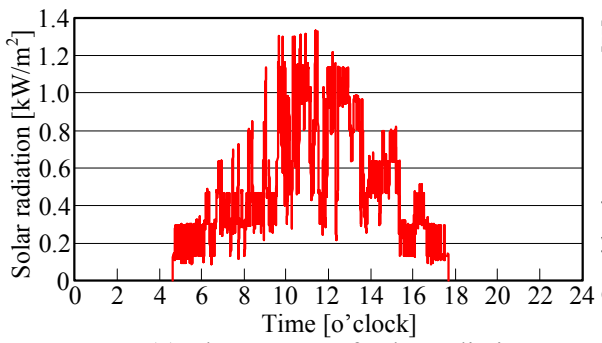

(a) The amount of solar radiation

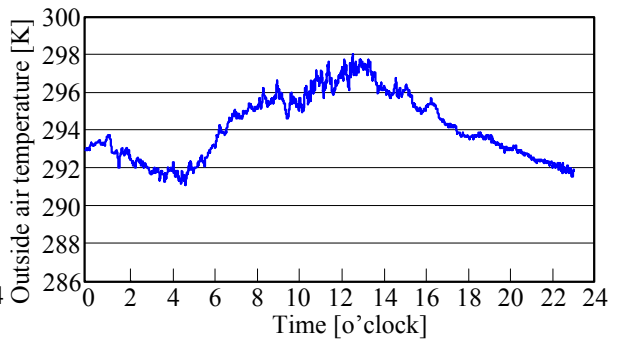

(b) Outside air tmeperature

Fig. 11 Weather observation 1-minute data in August 23, 2007 in Sapporo ${ }^{\text {) }}$

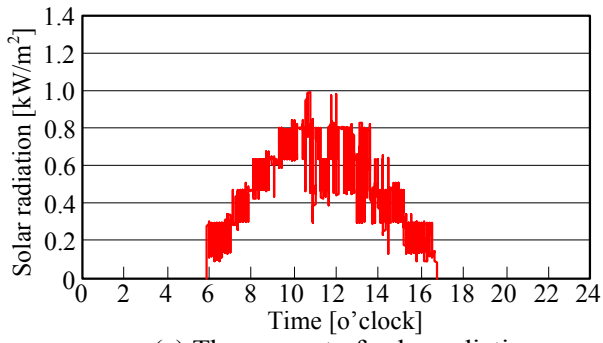

(a) The amount of solar radiation

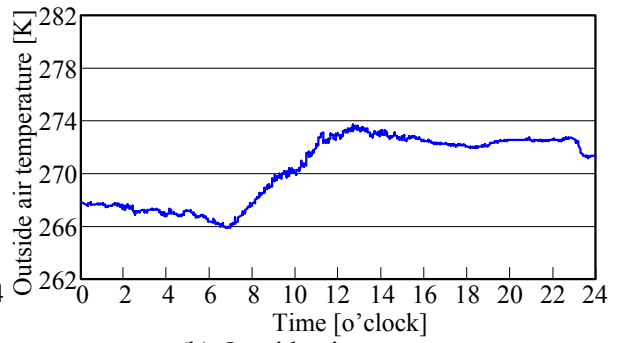

(b) Outside air tmeperature

Fig. 12 Weather observation 1-minute data in March 1, 2007 in Sapporo ${ }^{6}$

\subsection{Composition of the process gas}

Figures 8 and 9 show the process gas composition along the $x$ axis of the catalyst layer as predicted by the analysis. Figure 8 shows the composition of each gas with its respective molar flow rate. Fig. 9 expresses composition of each gas with its respective mass ratio. As shown in Fig. 8, the molar flow rate of hydrogen is larger than other gases in the composition. Distribution of the molar flow rate of hydrogen, and the time at which the hydrogen flow rate becomes stable are influenced by the magnitude of the solar irradiance input into the reactor. If there is little solar irradiance and there a short period of solar radiation fluctuation, the hydrogen generation rate may not reach the maximum possible. For example, when there is solar radiation fluctuation for 10 or less seconds with solar irradiance $250 \mathrm{~W} / \mathrm{m}^{2}$, the hydrogen generating rate is always smaller than maximum (about $0.008 \mathrm{~mol} / \mathrm{s})$.

As shown in Fig. 9, the mass ratio of the hydrogen in the process gas in the catalyst layer is smaller than that of the $\mathrm{CO}_{2}$ and $\mathrm{H}_{2} \mathrm{O}$. The compression storage system of reformed gas is introduced in FBSR as shown in Fig. 1. If $\mathrm{CO}_{2}$ and $\mathrm{H}_{2} \mathrm{O}$ are separated from reformed gas, it is effective in reducing the compressor's power consumption.

\subsection{Hydrogen generating rate}

Figure 10 shows the results of the analysis for the hydrogen generating rate as a function of sampling time. The stable time of the hydrogen generation rate is so short that much solar irradiance input to the reactor and outside air with a warm temperature. However, in 


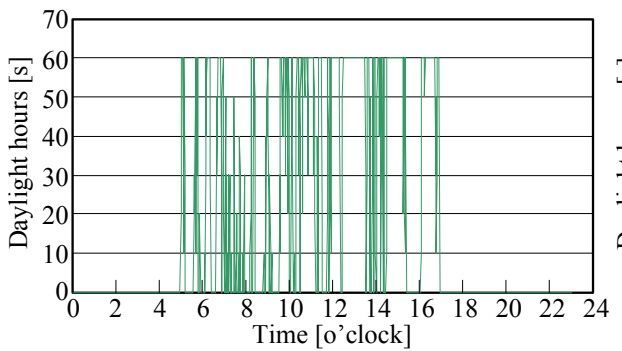

(a) August 23, 2007

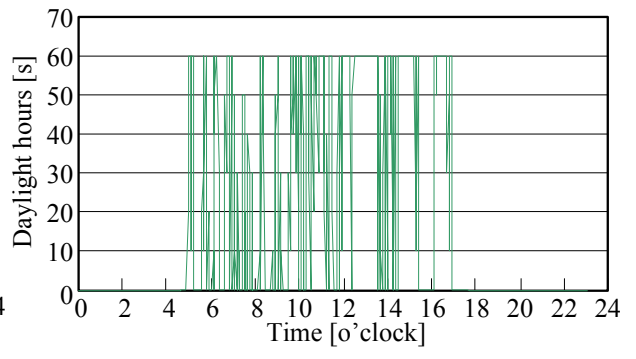

(b) March 1, 2007

Fig. 13 Daylight hours concerning the weather observation 1-minute data ${ }^{6}$

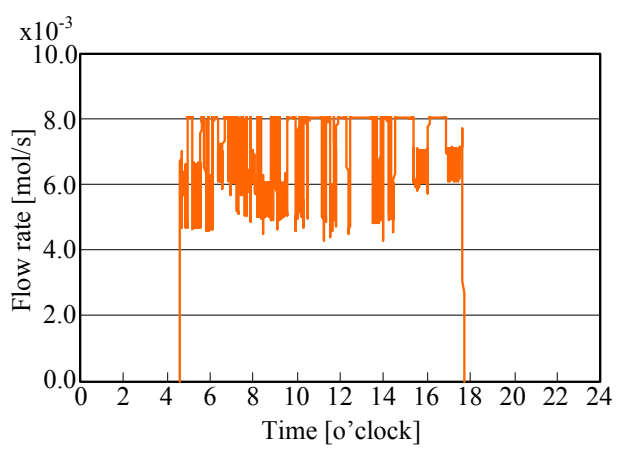

(a) August 23, 2007

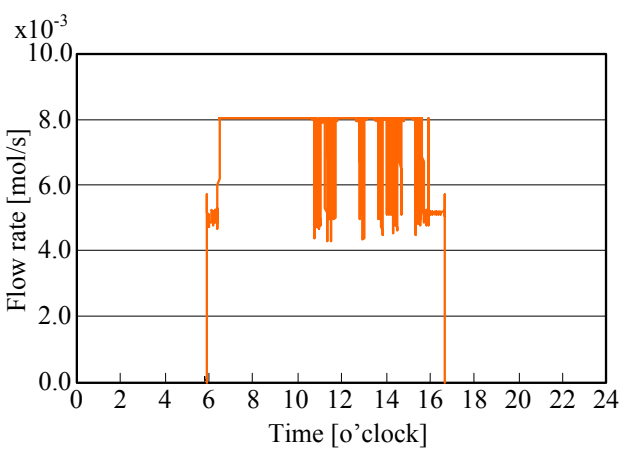

(b) March 1, 2007

Fig. 14 Characteristics of the hydrogen flow rate of FBSR

realistic weather conditions, it is expected that the solar radiation fluctuates in intervals of tens of seconds. So, data from an observed amount of global solar radiation is used, and the hydrogen generating rate of FBSR are investigated under these realistic conditions. In this paper, "Surface-weather-observation 1-minute data, 2007 Sapporo district meteorological observatory, Japan Meteorological Business Support Center ${ }^{6}$ " is used as observational data of the amount of global solar radiation, and outside air temperature.

\subsection{Hydrogen generating rate with fluctuating global solar radiation}

(1) Weather observation data

Figures 11 and 12 show the weather observation data (solar irradiance and outside air temperature) in 2007 August 23 and March 1 in Sapporo ${ }^{6}$. Further, Fig. 13 shows the observational data of the number daylight hours in each day ${ }^{6}$. The solar irradiance shown in Figs. 11 and 12 is a value from the daylight hours shown in Fig. 13. The hydrogen flow rate of FBSR is investigated using these data. In this section, proportion interpolation of the solar irradiance and the outside air temperature is considered in relation to the analysis results of Fig. 7 to Fig. 10, and the hydrogen flow rate in arbitrary weather conditions is obtained.

(2) The amount of hydrogen production, and the efficiency of the reforming component

Figure 14 shows the analysis result of each day. The hydrogen generating rate fluctuates a lot when comparing August 23 to March 1. This is because the fluctuation characteristics of the solar insolation at 6:00 a.m. to 10:00 a.m. differ greatly on each day as Fig. 11 (a) and Fig. 12 (a) show. Accordingly, it is thought that the solar insolation of this time zone on March 1 was stable (Fig. 12 (a)). On the other hand, it is expected that much of the solar insolation on August 23 (Fig. 11 (a)) was blocked by clouds. The analysis result of the amount of global solar radiation, the amount of hydrogen production, and the efficiency of the reforming component of each day is shown in Table 3. The differences in the amount of hydrogen production is small (1.17 times) when compared to the differences in the amount of global solar radiation (1.32 times). Moreover, the efficiency of the reforming component on March 1 is larger than August 23. These analysis results show that the 
Table 3 Performance of the reforming component (expected value)

\begin{tabular}{|c|c|c|}
\hline & $\begin{array}{l}\text { August 23, } \\
2007\end{array}$ & $\begin{array}{l}\text { March 3, } \\
2007\end{array}$ \\
\hline The amount of global solar radiation per day & $18.5 \mathrm{MJ} / \mathrm{Day}$ & $14 \mathrm{MJ} /$ Day \\
\hline The amount of hydrogen production per day & 117 g/Day & $100 \mathrm{~g} /$ Day \\
\hline $\begin{array}{l}\text { Efficiency of a reforming component (The higher calorific } \\
\text { value of hydrogen / the amount of heat collections per day) }\end{array}$ & $42 \%$ & $47 \%$ \\
\hline
\end{tabular}

fluctuation characteristics of solar irradiance have a big effect on the hydrogen generating rate of FBSR. Accordingly, although the amount of production of hydrogen and the efficiency of the reforming component change with fluctuation of solar irradiance, the efficiency of the reforming component reduces if fluctuations of solar insolation occur frequently.

\section{Conclusions}

The reactor of the reforming component installed in FBSR is filled up with the catalyst. In this research, heat transfer analysis was used in this catalyst layer, and the relations between the supply of solar insolation and the hydrogen flow rate were investigated. As a result, the following conclusions were obtained.

(1) Fluctuation of solar radiation influences the hydrogen generating rate of FBSR greatly. Accordingly, when solar irradiance is unstable, the efficiency of the reforming component reduces. If fluctuations of the solar insolation are on the order of ten seconds, and they occur frequently under the same amount of global solar radiation, the amount of hydrogen production will reduce.

(2) The amount of hydrogen production of an FBSR was analyzed using the meteorological data of the cold district (Sapporo) on March 1 and August 23, 2007. The results showed that the efficiency of the reforming component of both representative days exceeded $40 \%$. This result shows that an FBSR can compete with the present commercial photovoltaic cells, even when taking into consideration the efficiency of a fuel cell, and power consumption of auxiliary machinery.

\section{Nomenclature}

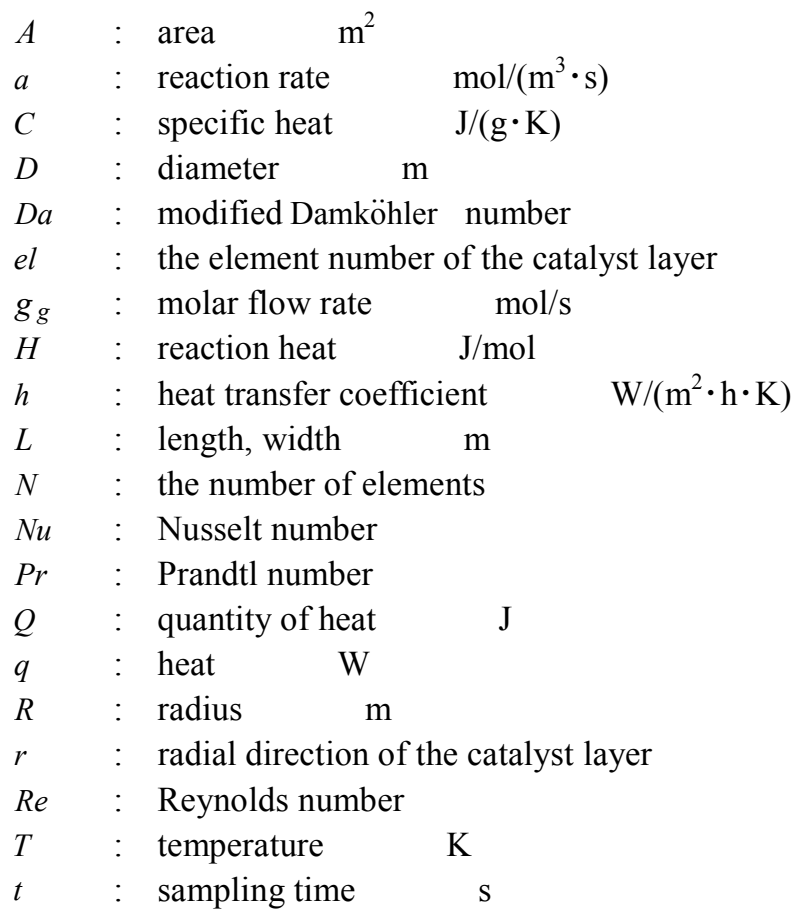




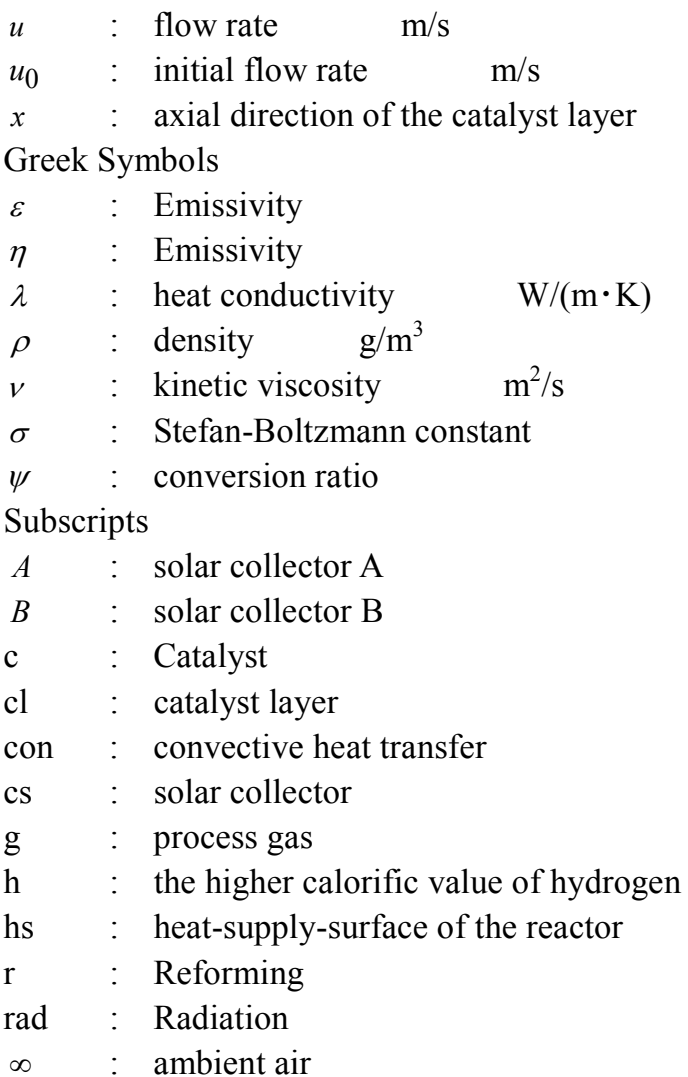

\section{Acknowledgments}

This work was partially supported by a Grant-in-Aid for Scientific Research (C) from JSPS.KAKENHI (20560204).

\section{References}

(1) Shin'ya OBARA and Itaru TANNO, Development of Distributed Energy System due to Bio-ethanol PEM Fuel Cell with Solar Reforming, Part 1-Evaluation of Basic Performance, Transactions of the Society of Heating, Air-Conditioning and Sanitary Engineers of Japan, 123, (2007), 23-32.

(2) Shin'ya OBARA and Itaru TANNO, Development of Distributed Energy System due to Bio-ethanol PEM Fuel Cell with Solar Reforming, Part 2-High-speed analysis of the operation plan using a neural network, Transactions of the Society of Heating, Air-Conditioning and Sanitary Engineers of Japan, 130, (2008), 33-42.

(3) Operation Prediction of a Bioethanol Solar Reforming System Using a Neural Network, Shin'ya OBARA and Itaru TANNO, Journal of Thermal Science and Technology, Vol. 2, No. 2, 2007, 256-267.

(4) Y. Usami, S. Fukusako and M. Yamada, Heat and Mass Transfer in a Reforming Catalyst Bed (Quantitative Evaluation of the Controlling Factor by Experiment), Transactions of the JSME, Series B, 67(359), (2000), 1801-1808.

(5) E. Akpan, A. Akande, A. Aboudheir, H. Ibrahim and R. Idem, Experimental, Kinetic and 2-D Reactor Modeling for Simulation of the Production of Hydrogen by the Catalytic Reforming of Concentrated Crude Ethanol (CRCCE) Over a Ni-Based Commercial Catalyst in a Packed-Bed Tubular Reactor, Chemical Engineering Science,62(12), (2007), 3112-3126.

(6) Surface-weather-observation 1-minute data, 2007 Sapporo district meteorological observatory, Japan Meteorological Business Support Center, (2008), Tokyo. 